\title{
DIREITO E LITERATURA: UMA BUSCA PELA IGUALDADE DE TRATAMENTO AOS SOCIALMENTE INVISÍVEIS
}

\author{
Danielle Augusto Governo ${ }^{1}$ \\ Renato Bernardi ${ }^{2}$
}

\begin{abstract}
RESUMO: O presente estudo sobre a busca da efetivação do princípio da igualdade relacional para os grupos minoritários é complexo, visto que cada dia mais as minorias têm seu espaço de visibilidade diminuído, pois não possuem voz para efetivarem os seus direitos e conquistarem o respeito por sua identidade. Objetiva-se modificar os valores sociais e culturais por meio da desconstrução do discurso da servidão voluntária, que marginalizam os indivíduos. Neste sentido, foi utilizado o método dedutivo de investigação científica. Assim, observa-se que é relevante reconhecer a igualdade relacional e promovê-la, com o intuito de gerar o empoderamento das minorias.
\end{abstract}

PALAVRAS-CHAVE: Direito e literatura; Critério; Minorias no Brasil; Discurso da servidão voluntária; Igualdade relacional.

\section{RIGHT AND LITERATURE: A SEARCH FOR THE EQUAL TREATMENT OF THE SOCIALLY INVISIBLE}

ABSTRACT: The present study about the search for the effectiveness of the principle of relational equality for minority groups is complex, because more and more minorities have their visibility space diminished, since they do not have the voice to realize their rights and gain respect for their identity. It wants to modify social and cultural values through the deconstruction of the discourse of voluntary servitude, which marginalize individuals. In this sense, the deductive method of scientific research was used. This way, it is important to recognize relational equality and to promote it, with the aim of generating the empowerment of minorities.

KEYWORDS: Law and literature; Criterion; Minorities in Brazil; Discourse of voluntary servitude; Relational equality.

\footnotetext{
${ }^{1}$ Bacharel em Direito pela Faculdade do Norte Pioneiro - FANORPI. É Pós-graduanda em Direitos Humanos e Ressocialização pela Faculdade Venda Nova do Imigrante - FAVENI. É Especialista em Direito do Trabalho e Previdenciário pelo PROJURIS Estudos Jurídicos. Atua como advogada na área criminalista, em especial no Tribunal do Júri. Integrante dos Grupos de Pesquisa Democracia e Direitos Fundamentais; A Interferência do Estado na Vida da Pessoa Humana - INTERVEPES; e Direitos Fundamentais e a Sistematização Precedentalista Vinculante no Brasil.

2 Doutor em Direito do Estado (sub-área Direito Tributário) - PUC-SP. Professor efetivo dos cursos de Bacharelado, Mestrado e Doutorado, Coordenador do TCC e Membro da Comissão de Coordenação do Programa de Mestrado em Ciência Jurídica, todos da Faculdade de Direito do CCSA - UENP, Campus de Jacarezinho. Coordenador Pedagógico do PROJURIS Estudos Jurídicos Ltda. Procurador do Estado de São Paulo desde 1994.
} 


\section{INTRODUÇÃO}

O direito e a literatura envolvem-se de um modo fascinante, com o objetivo de mostrar a realidade humana de uma forma compreensível a todos, seja branco, negro, mulher, idoso, índio, rico, deficiente físico, pobre, enfim, a todos que se dispuserem a debruçar sobre ela com a curiosidade, que é inerente ao ser humano.

Neste ínterim, a crônica, apontada no texto, conta a história de náufragos de um transatlântico que estavam em um barco salva-vidas perdido no mar, quase sem comida, e, diante dessa realidade, viram a antropofagia como solução. Porém, não sabiam qual critério utilizarem para escolherem as primeiras pessoas das classes inferiores a serem sacrificadas em prol da primeira classe e todos começaram a discutir, sem encontrarem nenhuma resposta, o que causou grande reboliço no barco, o qual acabou virando e todos vieram a ser comidos pelos tubarões, que, como é cediço, não têm critério algum para se alimentar.

Metaforicamente, esta crônica é profundamente atual, tendo em vista a realidade social dos grupos minoritários no Brasil, como será visto no desenvolvimento da pesquisa em tela, e que aceita esta situação como verdade irrefutável.

O problema a ser enfrentado baseia-se na questão de como transformar, de forma cultural e social, a conformação das minorias em aceitarem o mito de que realmente devem ser oprimidas e é isso que o princípio da igualdade relacional, que é a igualdade como capacidade do indivíduo, irá efetivas por meio de políticas públicas do Estado e mudanças valorativas na cultura da sociedade de modo abrangente.

O objetivo do presente trabalho é refletir sobre o direito e a literatura, em especial, a respeito da crônica, para se ilustrar como ocorre a marginalização das minorias sociais no Brasil, atacada pelos tubarões dos tempos atuais e, por consequência, trazer à baila o princípio da igualdade relacional como ferramenta de emancipação dessas minorias na sociedade brasileira.

A escolha do tema é justificada pelo fato de que a circulação de estigmas sociais dos indivíduos minorizados auxilia no discurso da servidão voluntária e, consequentemente, na marginalização dessas pessoas, que não encontram respaldo no Estado, na sociedade e nem em suas próprias crenças, visto que acredita ser "justo" a sua situação de oprimido, o que, peremptoriamente, não deve ser mais alimentado, já que é contrário aos preceitos eleitos na Constituição Federal de 1988. 
Para tanto, será tratado a relação do direito e a literatura, mas, principalmente, será analisada a crônica Critério, com o objetivo de explorar as questões das minorias, bem como a sua conceituação e a sua invisibilidade social no Brasil.

Posteriormente, será visto o estudo sobre o discurso da servidão voluntária, em que as pessoas escolhem e buscam ser servas de uma outra pessoa, como se esta lhe fosse superior e isto aplicado ao caso das minorias, encaixa-se detalhadamente bem, pois os grupos minoritários, além de não terem voz, aceitam essa invisibilidade social e não lutam pelo o seu lugar igualitário na sociedade.

Será analisado como o conceito e as críticas do princípio da igualdade relacional, mas, sobretudo, a sua relevância e utilidade na busca de transformação dos valores que permeiam a sociedade no tocante às minorias sociais e sua exclusão.

Cumpre mencionar que a metodologia utilizada foi o método dedutivo, haja vista o presente trabalho partir de análises em obras existentes acerca do assunto, amparando-se principalmente nas obras de doutrinadores da ciência jurídica, da literatura também, além da legislação e das notícias, que surpreendem pelo processo de exclusão que causam às minorias, ou seja, faz-se uso da dedução para se alcançar uma conclusão a respeito do assunto ora debatido.

Dessa maneira, pretende-se, com o presente artigo, fazer com que as abordagens adotadas sobre as minorias, de um modo geral, se modifiquem, ou melhor, ajudem na transformação cultural, que urge para a sociedade e o Estado, com o fim de que o discurso da servidão voluntária não faça mais parte da realidade brasileira, mas, ao contrário, que a igualdade relacional seja o debate principal da nação, o que promoverá o empoderamento dos grupos minoritários em face às suas diversidades.

\section{DIREITO E LITERATURA: ANÁLISE DA CRÔNICA “CRITÉRIO”, DE LUIS FERNANDO VERÍSSIMO, SOB O VIÉS DAS MINORIAS INVISÍVEIS NO BRASIL}

Neste capítulo inicial, será estudado a ciência jurídica relacionada com a literatura, bem como a contextualização de crônica com a questão das minorias do Brasil, que se encontram sem voz e poderes nas esferas privadas e públicas dos direitos fundamentais.

De início, deve-se ter em mente que o direito é uma ciência, que tem como objeto os acontecimentos políticos, sociais e culturais da história humana.

Diante desta afirmação verossímil, é mister destacar que: 
O Direito adquire, historicamente, a feição que se lhe atribui. Por isso, não é um fenômeno estável e sofre mudanças, em seu conceito, na visão que se tem dele, no conjunto de suas práticas concretas, e também na sua função social. O Direito, nesse sentido, se aprimora, ou se empobrece, conforme o estado da evolução social. Por isso, em formas sociais retrógradas, também se terá uma redução social da significação do Direito, e, em sociedades estruturadas em torno de premissas de liberdade, igualdade, solidariedade e formação humana, como reflexo, ter-se-á no Direito a expressão das conquistas de patamares morais de correlação indivíduo- indivíduo, indivíduo-grupo, grupo-indivíduo. Por isso, as grades sociais definem muito de como o Direito se configura a cada contexto. (BITTAR; ALMEIDA, 2018, p. 587)

A ciência jurídica possui múltiplos significados, que abrange todas as magnitudes inimagináveis pelo homem, sendo que ela relaciona-se com outras ciências humanas, como a história, a filosofia, a antropologia, a sociologia, a psicologia e, em especial, com a literatura.

Neste sentido, a literatura é uma ciência, uma expressão da sociedade e do homem, com uma incrível capacidade de causar perplexidade em quem a confronta, enfim, é uma arte humana.

A literatura é capaz de transmitir épocas, instituições e realidades, sempre carregada de ideologismo de seu escritor e mostrando o ponto de vista da pesquisa realizada.

Versando a respeito da beleza da literatura, escreve Afrânio Coutinho (2016, p. 78):

A literatura, como toda arte, é uma transfiguração do real, é a realidade recriada, através do espírito do artista e retransmitida através da língua para as formas, que são os gêneros, e com os quais ela toma corpo e nova realidade. Passa, então, a viver outra vida, autônoma, independente do autor e da experiência de realidade de onde proveio. Os fatos que lhe deram às vezes origem perderam a realidade primitiva e adquiriram outra, graças à imaginação do artista. São agora fatos de outra natureza, diferente dos fatos naturais objetivados pela ciência ou pela história ou pelo social. O artista literário cria ou recria um mundo de verdades que não são mais medidas pelos mesmos padrões das verdades ocorridas. Os fatos que manipula não têm comparação com os da realidade concreta. São as verdades humanas gerais, que traduzem antes um sentimento de experiência, uma compreensão e um julgamento das coisas humanas, um sentido de vida, e que fornecem um retrato vivo e insinuante da vida. A Literatura é, assim, vida, parte da vida, não se admitindo possa haver conflito entre uma e outra. Através das obras literárias, tomamos contato com a vida, nas suas verdades eternas, comuns a todos os homens e lugares, porque são as verdades da mesma condição humana.

Assim, nota-se que a literatura possui um vasto arcabouço de dados e relatos históricos de uma certa época, mostrando o passado com o intuito de ajudar no presente e futuro, isto é, ela é capaz de traduzir a humanidade. 
Como não poderia ser diferente, a arte literária é um ambiente propício para a criação do homem, por meio de uma narrativa sutil, com o desiderato de apresentar críticas. Em outras palavras, a literatura é uma salutar alternativa, visto que se tem no discurso literário uma delicadeza, que, muitas vezes, permite-se colocar "o dedo na ferida". (TRINDADE, 2008)

Nessa esfera propícia aos debates e questionamentos, a literatura e o direito andam de mãos dadas como se fossem um casal de enamorados no sentido figurado, haja vista que:

\begin{abstract}
A literatura é como o sorriso da sociedade. Quando a sociedade ela está feliz, o espírito se lhe reflete nas artes e, na arte literária, com ficção e com poesias, as mais graciosas expressões da imaginação. Se há apreensão ou sofrimento, o espírito se concentra grave, preocupado, e então, histórias, ensaios morais e científicos, sociológicos e políticos, são-lhe a preferência imposta pela utilidade imediata. (COUTINHO, 2008, p. 85)
\end{abstract}

Desse modo, a literatura é uma ferramenta auspiciosa, na hipótese de se ter em perspectiva um processo de autorreferenciação, o qual advém de um processo de reconstrução das próprias pessoas a partir de sua ocupação em reconstruir seus dicionários diante da transitoriedade da história humana, segundo afirma Roberto Bueno (2011).

Nesse contexto, a ligação entre direito e literatura se dá em três aspectos diversos, quais sejam, o direito como literatura, no qual a investigação é realizada em torno do estudo da retórica e, mormente, é possível comparar os métodos de interpretação entre os textos literários e jurídicos; já no direito da literatura, analisa-se a dimensão da liberdade de expressão e a história da censura sob a visão jurídica; e, por fim, porém não menos relevante para este estudo, o direito na literatura vem em busca de questões mais profundas a respeito do direito, da justiça e do poder, exemplificativamente, nos textos literários e não nas obras de direito. (RAMIRO, 2012)

Cumpre destacar que falar de direito é, inerentemente, tratar da linguagem, bem como usar literatura é utilizar a linguagem. Assim, o direito faz uso da linguagem, das narrativas para se obter informações e subsídios para compreender o meio social e formar o caldo de cultura, visto que "[...] nenhum conjunto de instituições jurídicas ou normas existe em separado das narrativas que o situam e lhe proporcionam significado" (COVER, 2016, p. 188).

As palavras de Arnaldo Sampaio de Moraes Godoy (2002, p. 21) realçam a importância de tal relação entre direito e literatura: 


\begin{abstract}
A Literatura presta-se a oferecer informações e subsídios para compreensão do meio social, que é o caldo de cultura onde desenvolve-se o Direito. Embora a linguagem literária tenha matiz artístico, e a linguagem jurídica, um modelo científico, aquela expressa o que a sociedade pensa dessa. As linguagens são distintas, não há dúvidas. A linguagem jurídica presta-se a resolver conflitos, em plano prático, e a cogitar de si mesma, em plano mais teórico.
\end{abstract}

Nesse sentido, o direito, ou melhor, a linguagem jurídica apresenta termos complexos para as pessoas leigas, que estão situadas fora do "mundo do direito" e a literatura vem de encontro a essa questão, com o intuito de facilitar o entendimento da ciência jurídica, visto que a literatura possui vocabulário mais simples, não técnico e de fácil contextualização, como pode ser observado em inúmeras obras literárias tanto brasileiras como internacionais.

Diante dessa verdade irrefutável, tem-se o fato de que é imprescindível estudar o direito e a literatura a partir de sua interdisciplinaridade, uma vez que não se tratam de ciências isoladas, pelo contrário, necessitam dessa relação para se fazerem valer e, principalmente, atingirem determinados assuntos que a sociedade prefere olvidar-se, como, por exemplo e objeto desta pesquisa, a questão das minorias no Brasil, que, de modo irônico, se trata de uma grande parcela da sociedade sem voz e, o que é mais grave, conformada com esta humilhante situação.

Hodiernamente, em face desta profunda relevância, há no Brasil, diversos movimentos que estudam esta interdisciplinaridade de direito e literatura, sendo que há seminários, simpósios, grupos de debates, grupos de pesquisa, linhas de pesquisa em pósgraduações em lato sensu e stricto sensu, disciplinas em universidades direito, entre outros.

A título de exemplo do afirmado acima, há o programa da Universidade do Vale do Rio dos Sinos (UNISINOS), o grupo de pesquisa da Universidade Federal de Santa Catarina (UFSC) e a Associação dos Juízes do Rio Grande do Sul (AJURIS), que se debruçam para estudar a literatura e o direito. (SOARES; OLIVEIRA JÚNOR, 2012)

Ademais, tem-se o programa de televisão Direito \& Literatura, apresentado pelo prof. Lenio Luiz Streck, o qual é um projeto criado, de início, pelo Instituto de Hermenêutica Jurídica (IHJ) e passou, posteriormente, a ser dirigido e patrocinado pela Rede Brasileira Direito e Literatura (RDL), sendo produzido e coordenado por André Karam Trindade. Este programa televisivo é transmitido semanalmente pela TV Unisinos e TV Justiça, no qual se apresenta debates entre professores de diversas áreas do conhecimento humano, com o escopo de propagar a interdisciplinaridade entre direito e literatura, e também de mostrar um novo ponto de vista da ciência jurídica e, por meio disso, entender os fenômenos sociais, políticos e 
culturais dos tempos atuais, trazendo obras literárias, que marcaram as pessoas e as ligando aos temas do direito de modo simples e, ao mesmo tempo, profundo. (RDL, 2018)

Com esse mesmo desiderato, tem-se o Simpósio Regional Direito e Cinema em Debate - DIRCIN, o qual é um simpósio desenvolvido e dirigido pelo curso de Programa de Pós-Graduação em Ciência Jurídica da Universidade Estadual do Norte Pioneiro (UENP) em parceria com o PROJURIS Estudos Jurídicos, sob a coordenação geral do Professor Doutor Renato Bernardi, que ocorre anualmente no mês de maio, desde o ano de 2015, e que a partir do ano de 2017 iniciou-se a proposta da música e da literatura relacionada com o direito, o que foi uma novidade muito bem recepcionada, tendo em vista que até então o simpósio era voltado apenas para o direito e o cinema, o que permitiu uma grande abertura da ciência jurídica para com as artes do homem. (DIRCIN, 2018)

Nesse diapasão, como o objeto de estudo deste trabalho é estudar a questão das minorias, é preciso vê-la a partir da literatura e isso é o que faz o gaúcho Luís Fernando Veríssimo (1990), em sua crônica Critério, a qual narra a história de náufragos de um transatlântico, que estavam dentro de um barco salva-vidas perdido no mar e já tinham acabado com toda a comida, sendo que a antropofagia era a única opção de sobrevivência; diante disto, a primeira classe começou a propor sobre quem seriam as primeiras pessoas a serem sacrificadas pelas outras, sendo que as mulheres, os idosos, os jovens, os gordos, os religiosos e os magros eram apontados como possíveis opções, porém para cada minoria havia uma justificativa para não serem mortos, como, por exemplo, o caso dos mais velhos que alegaram ser uma falta de respeito para com eles e também o fato de serem difíceis de mastigar; o que gerou um grande dilema: qual critério utilizar para decidir quem seriam as vítimas? Mas, as segundas e terceiras classes ficaram indignadas com tal situação, visto que não foram consultadas em nenhum momento, o que fez um dos passageiros dessas classes questionarem: "Cumé que é?" (VERÍSSIMO, 1990, p. 59), o que foi criticado pelos passageiros da primeira classe; em ato contínuo, propuseram comer os indecisos, o que gerou um reboliço na primeira classe acuada; posteriormente, um ajudante de maquinista levantouse e disse: “- Náufragas e náufragos — começou — Neste barco só existe uma divisão real, e é a única que conta quando a situação chega a este ponto. Não é entre velhos e jovens, gordos e magros, poetas e atletas, crentes e ateus... É entre minoria e maioria." (VERÍSSIMO, 1990, p. 59); e depois, apontou em direção à primeira classe e afirmou para todos comerem a primeira classe, que eram a minoria, causando um novo reboliço, protestos, brigas e revanchismo, o que fez com que o barco 
salva-vidas virasse e todos, “[...] sem distinção de classes, foram devorados pelos tubarões. Que como se sabe, não têm nenhum critério." (VERÍSSIMO, 1990, p. 59)

Nesta crônica, percebe-se como Luís Fernando Veríssimo fala e trata das minorias de forma irônica, mas também apresenta um discurso naturalizado dessa parcela da sociedade, a qual não sabe ser dona de seu próprio discurso, em que pese ter alguns direitos e deveres, como se verá nos próximos capítulos.

Por meio desta crônica de Luís Fernando Veríssimo (1990), é possível perceber a suposta maioria discutir qual critério utilizar para se alimentar primeiro das "minorias" ali presentes na embarcação, sendo que estas eram, na realidade a maioria no barco salva-vidas, porém não tinham voz, ou seja, eram invisíveis ao restante dos que estavam ali.

Nessas pegadas, é indispensável ver o que vem a ser minorias no Brasil, que devem ser compreendidas como grupos de pessoas vulneráveis, que formam uma grande parcela da população, com pouca representatividade social, cultural, política, jurídica e econômica, em razão de suas características étnicas, raciais, econômicas, culturais, entre outros aspectos, e que são tratadas de forma diminuída pelo Estado e pela sociedade, como se aquelas não fizessem parte dessa.

O termo "minorias" é usado de forma genérica para fazer referência a grupos sociais específicos que são entendidos como integrantes de uma menor parte da população, sendo diferenciados por suas características étnicas, religiosas, cor de pele, país de origem, situação econômica, entre outros. As minorias estão geralmente associadas a condições sociais mais frágeis. (RODRIGUES, 2018, online)

Cumpre esclarecer que, muitas vezes, a chamada "minorias" não é, na verdade, uma pequena quantia de pessoas pertencentes a determinado grupo social, mas pelo contrário, acabam formando a maioria da população brasileira, ou seja, não se trata de uma questão quantitativa, mas sim de representação social. (FRASER, 2001)

Desse teor, Claudio Márcio do Carmo (2016, p. 205) apresenta as características básicas das minorias:

1) vulnerabilidade jurídico-social - por ser um grupo institucionalizado pelas regras do ordenamento jurídico-social vigente, logo, muitas vezes não acampado pelas políticas públicas, a razão para lutar por voz e reconhecimento societário de seu discurso;

2) identidade in statu nascendi - porque se apresenta sempre in statu nascendi, compreendido como uma entidade em formação que se alimenta da força e do ânimo dos estados nascentes ou de um eterno recomeço; 
3) luta contra-hegemônica - parte sempre de uma constante luta pela redução do poder hegemônico, mas, normalmente, sem objetivo de tomada do poder pelas armas;

4) estratégias discursivas - uso de estratégias de discurso e de ações demonstrativas (passeatas, por exemplo) como os principais recursos de luta na atualidade.

Dessa maneira, minorias são a recusa de consentimento social, isto é, um dissenso na procura de uma abertura contra-hegemônica da sociedade fechada.

Nessa seara, há vários grupos tidos como minorias no Brasil, como os citados, exemplificativamente, na crônica "Critério" (VERÍSSIMO, 1990), como as mulheres, os negros, os índios, os homossexuais, os idosos, os pobres, os deficientes físicos, os presos, entre outras categorias de pessoas tidas como pertencentes às minorias, que têm sua identidade negada.

Nota-se que "a desigualdade estrutural entre grupos está diretamente ligada à existência de mecanismos que concentram oportunidades nas mãos de certos segmentos sociais" (MOREIRA, 2017, p. 192), o que acarreta o tal fechamento contra-hegemônico social, uma vez que grupos majoritários criam redes de influência que conseguem benefícios significativos do monopólio de acesso à oportunidades.

A propósito, pertinentes e explicativas são as palavras de Adilson José Moreira (2017, p. 192-193):

Tendo em vista o fato de que a estratificação deriva de critérios que marcam a diferença entre grupos, ela se torna um princípio de organização de valores e práticas sociais em uma série de contextos. Assim, categorias como raça e sexualidade estruturam relações assimétricas entre grupos em diversas instâncias, sendo que a operação de redes de influência garantidoras do controle de oportunidades e recursos reproduz diversos mecanismos responsáveis pela estratificação fundada nessas categorias. Tais mecanismos mantêm uma condição sistêmica de desigualdade baseada não apenas em formas de discriminação direta, mas também em mecanismos excludentes que operam independentemente de atores sociais concretos.

Vê-se que há um caráter sistêmico que, por meio de práticas e sentidos culturais, acaba criando grupos discriminados nas diversas formas de interação humana.

A crônica em tela apresenta a seguinte questão: quem são os tubarões hoje? Esse círculo que carrega valores e preconceitos constroem os "tubarões sociais", que marginalizam e excluem as minorias, retirando seus direitos ou, muitas vezes, realizando a antropomorfização aos grupos minoritários em seu sentido contrário. 
Essa discriminação é fruto da marginalização social, ou melhor, da circulação de valores que determinam o lugar de cada indivíduo na sociedade brasileira, o que mantêm o indivíduo no "status quo", qual seja, em uma situação estrutural de desigualdade.

Nesse sentido, Adilson José Moreira (2017, p. 193-194), em alentada incursão no tema da marginalização das minorias, aponta:

A marginalização tem sido considerada como um obstáculo particularmente
significativo para a construção de uma sociedade democrática, porque ela
cria subclasses de pessoas que estão excluídas da plena participação social.
Esses grupos são discriminados e, função de sentidos culturais que
representam certas características como negativas; eles se tornam
socialmente salientes já que marcam uma diferença que funciona como
motivo de opressão. A marginalização mantém esses grupos em uma
situação de privação dos recursos que são necessários para a construção de
uma vida digna dentro de uma sociedade. A constante circulação de
preconceitos e estereótipos torna ineficaz medidas que procuram integrar
membros de grupos marginalizados.

Fincado neste entendimento, é preciso perceber que a marginalização obsta a participação de grupos no processo de decisão política, afastando os grupos minoritários de condições reais de modificar a sua realidade de opressão. (SARLET, 2015)

Como exemplo dessa exclusão que ocorre rotineiramente, têm-se o direito a banheiro para os transgêneros, as uniões homoafetivas, a questão do aborto, a relevância da legislação que procura proteger as parcelas hipossuficientes da sociedade, entre outros tristes exemplos que comprovam, indubitavelmente, que o Brasil é um país feito para poucos, metaforicamente.

Outrossim, tudo isso é refletido na falta de representatividade política, visto que a legislatura atual é composta por aproximadamente $80 \%$ (oitenta por cento) de homens brancos, ao passo que eram apenas $43 \%$ (quarenta e três por cento) dos candidatos que eram brancos, ou seja, nota-se que a sociedade vota em uma espécie de "homem superior". Além dessa prova de invisibilidade social, há o fato de que, por exemplo, há tão somente um único deputado federal que se declara como homossexual, sendo que inexiste índio eleito e as mulheres formam apenas $10 \%$ (dez por cento) do eleitorado. (DEPUTADOS, 2015)

Cumpre observar que na crônica, há um corte de ponto bem específico, no qual um sujeito que era passageiro da segunda e da terceira classes, que estavam caladas perante a discussão que se dava na primeira classe, manifestou-se perguntando: “Cumé que é?", o que mostra na própria linguagem, na grafia em si, no termo e na gíria, uma marcação de diferença social entre os náufragos das classes do transatlântico, restando claramente como o texto 
literário mostra o mundo nesses pequenos detalhes e, no caso em tela, a questão das minorais invisíveis. (VERÍSSIMO, 1990)

Como a linguagem, neste ponto, às vezes, além da crítica que se faz ao politicamente correto, é uma crítica também com relação às assimetrias do poder na sociedade, visto que a perfeição do texto literário são esses pequenos detalhes da construção linguística.

O produtor do discurso fica claro quando a discussão ocorre na primeira classe da embarcação, sem haver qualquer consulta aos passageiros das outras classes, que eram tidas como inferiores, ou seja, quem era maioria não tinha voz e nem era levado em considerado pelos que se achavam no direito de decidir por eles, como se fossem mais importantes para sobreviverem naquele contexto. (SMETAL, 2016)

Assim, é o que se sucede no Brasil, haja vista que a minoria, que, na realidade, não são poucos, têm apenas alguns direitos garantidos e pouquíssima visibilidade social, política, jurídica e econômica para intervirem nas instâncias de poder decisório, o que é facilmente percebível na literatura, nos cargos políticos, nos empregos, nas publicidades, nas novelas, entre outros espaços de voz.

\section{DISCURSO DA SERVIDÃO VOLUNTÁRIA E A CONFORMAÇÃO DAS MINORIAS}

Como se não bastasse as escassas garantias dos direitos dos grupos minoritários, há a pior adversária de toda mudança social: a conformação. Esta aceitação está no sentido da servidão voluntária do povo, que se sente satisfeito em agir em prol dos que acham superiores aos demais e que acreditam que isso não deve ser mudado de modo algum, visto que só assim a sociedade terá a sua devida evolução.

A servidão voluntária é uma teoria de Etienne De La Boétie (1982), em seu discurso, que trata do escravo feliz.

O discurso da servidão voluntária é uma obra escrita por Etienne De La Boétie, como sobredito, no ano de 1552, em que ele analisa as razões das pessoas deixarem-se escravizar, de modo cego, voluntário e feliz, para servir uma minoria tirana.

Nessas pegadas, o povo se conforma e se degola ao escolher o súdito ao invés da liberdade, aceitando o seu destino e, muitas vezes, acaba lutando por essa servidão. Nesse processo de escravidão feliz, o soberano torna-se um verdadeiro tirano ao conseguir seu poder para subjugar o povo.

Rev. de Direito, Arte e Literatura | e-ISSN: 2525-9911| Porto Alegre | v. 4 | n. 2 | p. 53 - 73 | Jul/Dez. 2018 
Segundo Etienne De La Boétie (1982), há três motivos que acarretam na servidão voluntária, quais sejam, o hábito, a covardia e a participação na tirania. O hábito pode ser explicado pelo fato de que as pessoas são ensinadas a servir, ou melhor, a serem escravizadas e conformadas a viver dessa maneira. Já a covardia ocorre porque os tidos escravos não têm força para lutar, o ardor da busca pela mudança, enfim, pela liberdade de sua realidade e, sabendo dessa verdade, os tiranos aproveitam para enfraquecer cada vez mais o povo escravizado, bestializando-os. Por derradeiro, a participação na tirania mostra a rede da servidão voluntária, que é frágil, visto que o tirano não ama, não é amado e não tem amigos, mas que se mantém em virtude da ambição de alguns e dele próprio.

Nesse sentido, Etienne De La Boétie (1982, p. 05) manifesta-se do seguinte modo:

Em primeiro lugar creio não haver dúvida de que, se vivêssemos com os direitos que a natureza nos deu e com as lições que nos ensina, seriamos naturalmente obedientes aos pais, sujeitos à razão e servos de ninguém. Da obediência que cada um, sem outra advertência que a de sua natureza, presta a seus pai e mãe todos os homens testemunham, cada um por si. Da razão que nasce conosco ou não, o que é uma questão debatida a fundo pelos acadêmicos e abordada por toda a escola dos filósofos, por ora não pensaria falhar ao dizer o seguinte: há em nossa alma alguma semente natural de razão que, mantida por bom conselho e costume, floresce em virtude e, ao contrário, frequentemente sufocada, aborta, não podendo enfrentar os vícios sobrevindos. Mas, por certo se há alga claro e notório na natureza, e ao qual não se pode ser cego é que a natureza, ministra de deus e governante dos homens, feznos todas da mesma forma e, ao que parece, na mesma fôrma, para que nos entreconhecêssemos todos como companheiros, ou melhor, como irmãos.

Esse raciocínio de Etienne De La Boétie mostra o quão o povo brasileiro está acostumado com a exclusão das minorias sociais, já que é cômodo para alguns esta subordinação da maioria da população pelos tiranos hodiernos.

Como exemplo do afirmado neste trabalho, tem-se o caso do magistrado Flávio Itabaiana de Oliveira Nicolau, da Vara Criminal do Rio de Janeiro, que proferiu a sentença nos autos n. 0229018-26.2013.8.19.0001, em que figuravam vinte e três réus, que participaram dos protestos nos anos de 2013 e 2014, sendo que foram fixadas penas que variam de cinco a sete anos de reclusão em regime fechado, por terem cometido o crime de associação criminosa e de corrupção de menores.

Nessa sentença, o juiz afirma que um dos acusados tem conduta social reprovável, “apesar de se tratar de uma pessoa da classe média" (STRECK, 2018, online).

E Lenio Luiz Streck (2018, online) aponta: 
[...] para o juiz, ser de classe média gera, automaticamente, a "presunção" de ser "gente boa". Classe média não pode decepcionar...! Então, quem não é classe média, está lascado. A frase do magistrado repete chavões do senso comum como, por exemplo, "apesar de rico ou branco, é ladrão" ou, a contrário sensu, "negro, mas honesto", "pobre, mas limpinho", etc, preconceitos deletérios que povoam o imaginário de um país que não consegue se livrar de suas raízes escravagistas e patrimonialistas.

Diante desta sentença e da análise de Etienne De La Boétie, em seu discurso de servidão voluntária, está clara a visão de que como está impregnado o preconceito de que as supostas maiorias são tidas como melhores quando comparadas com as minorias sociais e que isso é o que mantém a atual sociedade como está, pois somente, dessa maneira, seria possível melhorá-la, o que é uma falácia.

Diz-se falácia tendo em vista que é esta desigualdade estrutural que mantém o poder nas mãos de poucos e o que é pior, isto é aceito pelo povo, que não se revolta contra essa arbitrariedade social.

Discursos como este presente na sentença supracitada representam o que a sociedade manifesta, como, por exemplo, "eu até tenho amigos que são gays" e "eu sou tão democrata que até tenho amigos negros", sendo que tais frases são ditas de modo inconsciente pelo seu locutor, o que, mais uma vez, comprova as estruturas assimétricas do poder na sociedade e a conformação dos grupos minoritários, que não se sentem empoderados.

Até porque a própria minoria social utiliza este discurso, não se mobilizando contra ele, o que condiz com a ideia do contrapúblico subalterno, na qual há múltiplas esferas públicas, transversais, alternativas e contra-hegemônicas, em que as minorias poderiam tematizar a ausência de voz na esfera pública oficial e não acaba utilizando este instrumento, o que, cada vez mais, promove a descaracterização do seu traço humano, de acordo com Nancy Fraser (2014).

Nesse diapasão, o mito ou alegoria da caverna, do filósofo Platão, também expõe essa cultura do escravo feliz das minorias sociais, sendo que este mito é uma das passagens mais clássicas da história da filosofia, que consta no livro VI, de "A República", em que Platão debate a respeito da teoria do conhecimento, da educação na formação do Estado ideal e da linguagem. (CABRAL, 2018)

Este mito da caverna é uma metáfora de como as pessoas pertencentes aos grupos minoritários enxergam seu lugar na sociedade, uma vez que o que está fixado na cultura é tido como verdade absoluta e não pode, ou melhor, nem deve ser mudado. 
Neste sentido, há a Lei Municipal n. 3.629, do ano de 2003, no Rio de Janeiro, em que pró́be qualquer tipo de discriminação no acesso aos elevadores dos prédios residenciais, sejam eles utilizados pelos empregados ou moradores do prédio, conforme está disposto no artigo $1^{\circ}$, da legislação em tela: "Fica vedada qualquer forma de descriminação em virtude de raça, sexo, cor, origem, condição social, idade, porte ou presença de deficiência e doença não contagiosa por contato social no acesso aos elevadores", sendo que a lei fixou que o Poder Executivo seria o responsável para desenvolver ações de cunho educativo e de combate à discriminação ocorrida nesses lugares (artigo $8^{\circ}$, da lei em comento), o que nunca foi desenvolvido pelo Poder Executivo. (JUSBRASIL, 2003)

Em que pese haver a presente legislação, a maioria dos empregados continuam utilizando o elevador de serviço e entrando pelos fundos do local onde trabalham, já que se autoafirmam saberem quem são e qual o seu lugar na sociedade, totalmente alienados do seu "eu", isto é, conformados com a situação.

Perfilhando esta visão, Adilson José Moreira (2017, p. 204) aponta:

Como as pessoas afetadas têm poder limitado para transformar os sentidos culturais que legitimam práticas discriminatórias, elas acabam sendo convencidas de que não são capazes de estabelecer e alcançar objetivos pessoais. Mais do que impedir os membros de grupos minoritários de se reconhecerem como membros de uma sociedade que gozam do mesmo respeito, a circulação desses estigmas possuem outros objetivos que contribuem ainda mais para a exclusão. Estigmas são construídos para justificar práticas que impedem o acesso a oportunidades materiais para que as mesmas permaneçam nas mãos daqueles que têm poder de construir sentidos sociais.

Esta aceitação das minorias dificulta a saída destes grupos dessa posição, que lhe é designada, e ir à busca de um reconhecimento, de uma construção de identidade que não seja aquela que o outro lhe impôs.

\section{IGUALDADE RELACIONAL COMO “QUEBRA” DO PARADIGMA ATUAL DAS MINORIAS}

Neste terceiro e derradeiro capítulo, a pesquisa abordará o princípio da igualdade sob uma nova roupagem, que vai além das igualdades formal e material, uma vez que se mostraram insuficientes no processo de empoderamento das minorias, com o intuito de que a 
igualdade relacional seja uma ferramenta de não marginalização das pessoas que se conformaram com a sua situação.

Diferente do que se sucede na crônica Critério, de Luís Fernando Veríssimo, as minorias sociais necessitam se empoderar por meio de vias corretas, para que "o barco salvavidas não afunde e os tubarões devorem todos", visto que estes não possuem critério algum para se alimentarem.

Seguindo este entendimento, o princípio da igualdade relacional, o qual é uma teoria estudada, primordialmente, por Elizabeth Anderson e, depois, por Christian Schemmel (2011), nas respectivas obras, "What is the point of equality" (1999) e "Distributive and relational equality" (2011), apresenta as ferramentas certas para a mudança na realidade desses grupos minoritários juntamente com outros instrumentos, com o apoio do Estado e da sociedade.

O princípio da igualdade relacional vai além da igualdade formal e material, uma vez que desigualdade de status está ligada, de forma direta, à desigualdade material, o que faz com que se abandone as perspectivas conhecidas do princípio da igualdade.

Nessa seara, a igualdade relacional é mais do que um molde de distribuição de oportunidades aos grupos minoritários, ao passo que ela é, nesta teoria, uma forma de relação social.

Neste aspecto, oportuno o esclarecimento do que vem a ser o princípio da igualdade relacional, sob a perspectiva de Adilson José Moreira (2017, p. 173):

[...] o conceito de igualdade relacional enfatiza a importância das relações sociais para a justiça, o que requer a consideração da forma como relações de poder e dominação estruturam interações sociais entre diferentes grupos. Eles asseveram que preocupações exclusivas com questões distributivas não são capazes de desconstruir padrões de interação social que reproduzem relações hierárquicas baseadas em relações de dominação.

[...] uma sociedade democrática fomenta relações sociais que expressam respeito pelas pessoas. Embora o tema do respeito não esgote as reflexões sobre igualdade relacional, ele ocupa um importante papel dentro dessa teoria. O conceito de igualdade relacional parte das preocupações com as desigualdades de status presentes em sociedades democráticas, uma questão que guarda relações próximas com o tema estima social.

Assim, segundo esta teoria, a efetivação da justiça está subordinada à construção de relações socialmente igualitárias, com o intuito de destruir o discurso da servidão voluntária, que impera na sociedade brasileira. 
A igualdade, sob esta visão, seria a pressuposição da universalidade da igualdade moral dos indivíduos, porém essa premissa tem tanto um caráter negativo como um positivo. (MOREIRA, 2017)

O lado positivo buscar dar fim a todas as formas de opressão responsáveis pela formação de relações de dominação, marginalização e estigma dentro de uma sociedade, sendo que traços biológicos e psicológicos ou formas de identidade socialmente organizadas não devem ser usadas para degradar as pessoas.

Já no outro aspecto, os estudiosos dessa teoria também mostram parâmetros a partir dos quais os indivíduos podem se posicionar em face aos outros a partir de uma posição igualitária, o que seria um requisito fundamental para a formação de uma comunidade política, na qual não haveria relações assimétricas, pois todos reconheceriam o outro como um agente e o direito dele de participar de processos deliberativos da mesma maneira, mas as distinções de status seriam admitidas, como, “[...] por exemplo, entre pessoas que ocupam diferentes cargos dentro de instituições públicas ou privadas, nós podemos condená-las quando estão baseadas em critérios que não possuem valor moral.”(MOREIRA, 2017, p. 173)

Dessa maneira, no primeiro viés, tem-se um processo que valoriza o ser humano, ao passo que, no outro, existe um processo de distinção arbitrária de outros indivíduos.

Contudo, deve-se se ter em mente que as diferenças de estima estão, intimamente, relacionadas com diferenças de respeito entre pessoas, o que é perigoso para a sociedade.

Mas, mesmo assim, tal teoria é profundamente relevante, uma vez que trabalha como uma ferramenta de emancipação dos grupos minoritários, dando atenção à autonomia da pessoa em si. (NUNES JÚNIOR, 2009)

Para melhor iluminar a utilidade deste princípio sob essa nova roupagem, indispensável citar o excerto de Adilson José Moreira (2017, p. 174):

O igualitarismo relacional que ora abordamos propõe um modelo de sociedade no qual as instituições sociais criam as mesmas condições para todos os indivíduos, o que impede a criação de hierarquias de status entre eles. Relações de dominação não apenas impedem a construção de solidariedade social, mas também constituem por si mesmas formas de tratamento injusto entre indivíduos, pois envolvem a subjugação nessas relações. Relações sociais desiguais fundadas em hierarquias de status impedem que as pessoas possam desenvolver um senso de respeito próprio, como pessoas que podem atuar livremente como agentes e serem reconhecidas como tal.

Reconhecer a igualdade do outro significa também ter a disposição de tratar os interesses dele com a mesma validade com que uma pessoa trata as próprias. Mais do que isso, essa disposição em considerar os interesses do 
outro da mesma forma significa abrir um espaço para justificação desses interesses.

Nota-se que esta teoria tem como desiderato principal apostar na capacitação dos indivíduos, ou seja, o princípio da igualdade relacional é também visto como capacidade, visto que se relaciona com as liberdades pessoais que os indivíduos possuem para realizar ações e atingir os objetivos necessários para o gozo de emancipação pessoal.

Tal capacitação para a realização do bem-estar das pessoas pertencentes aos grupos minoritários pode ser auferida de duas maneiras, quais sejam, o primeiro modo é analisar o conjunto dos funcionamentos desenvolvidos para ser identificado com o bem-estar que os indivíduos gozam, tendo em vista que essa capacitação é uma liberdade para estes obterem o bem-estar; já o outro modo, é a liberdade de atuação do agente, em que ele busca seus objetivos próprios, sem qualquer ligação com o seu bem-estar. (ANDERSON, 1999)

Em que pese serem diferentes, estas duas maneiras estão relacionadas entre si, haja vista que a pessoa pode fixar a procura do bem-estar como um escopo da sua liberdade como uma agente e também pode se ver impossibilitada de buscar os objetivos que estão ligados com a condição de agente, o que conduz a uma perda da qualidade do seu bem-estar. (SCHEMMEL, 2011)

Outro ponto que deve ser analisado é o papel contramajoritário que o Supremo Tribunal Federal exerce, seguindo o raciocínio do princípio da igualdade relacional, uma vez que tem a função de proteger as minorias na realização dos direitos fundamentais em face dos Poderes Executivo e Legislativo, os quais representam os interesses dos grupos majoritários da sociedade brasileira:

Diante do painel apresentado até o momento, o Supremo Tribunal Federal no desempenho da jurisdição constitucional, tem proferido, comumente, decisões de caráter flagrantemente contramajoritário, em sólida demonstração de que os julgamentos da Suprema Corte, quando assim proferidos, objetivam preservar, em atuação fiel dos mandamentos constitucionais, a intangibilidade de direitos, interesses e valores que identificam os grupos minoritários colocados em situação de vulnerabilidade jurídica, social, econômica ou política e que, por efeito de tal condição, são reduzidos a objeto de intolerância, de perseguição, de discriminação e de injusta exclusão. (RANGEL, 2017, online)

O Supremo Tribunal Federal deve atuar de modo que o Estado Constitucional Democrático Brasileiro não seja diminuído a uma mera significação político-jurídica sem conteúdo e reflexo prático, tendo em vista que os grupos majoritários não podem nunca se sobrepor aos princípios e interesses previstos na Constituição Federal de 1988. 
Além disso, tem-se o fato de que o próprio indivíduo deve começar, a partir de si, uma revolta contra a sua situação de oprimido e de violência causado pela sociedade e pelo Estado, o que geraria um início de modificação nos grupos minoritários e no respeito às identidades de cada pessoa. Calha oportuna, neste ponto, a adequada observação de Edward Portis (1988, p. 457):

Uma concepção segura da própria identidade permite que o indivíduo possa ter uma existência autônoma. Ele pode pôr suas experiências em perspectiva e considerar diferentes caminhos a serem tomados. A negação dessa possibilidade fará com que ele seja acometido por uma ansiedade existencial que ocasionará o desenvolvimento de um senso de inconsistência interna. Assim, a percepção de que o mundo social está repleto de ameaças permanentes impede a construção de um sentimento integrado da personalidade. Esse é o motivo pelo qual devemos ver a formação de um senso de pertencimento social como uma necessidade básica. A cidadania abre espaço para que o indivíduo possa ter uma vida plena na medida em que ele pode integrar diferentes aspectos da sua identidade.

Por fim, tendo em vista o caráter de "quebra" de paradigma da igualdade relacional no atual contexto, observa-se que a igualdade é um instrumento necessário para a erradicação da subordinação social dos grupos minoritários, o que exige uma transformação cultural, fator relevante na luta diária em face dos estigmas sociais, porquanto a igualdade de direitos busca eliminar práticas sociais e valores culturais, que mantêm determinadas minorias sociais em uma quase eterna situação estrutural de desvantagem sem qualquer esperança de novos horizontes.

\section{CONSIDERAÇÕES FINAIS}

Diante de todos os argumentos expendidos no presente trabalho, entende-se plenamente que as mudanças por que passam a sociedade obrigam os pesquisadores, instituições e grupos sociais a pesquisar, discutir, orientar-se e atualizar-se quanto aos aspectos sociais, jurídicos, psicológicos e institucionais dessas mudanças no tocante à emancipação das minorias sociais no Brasil.

Por isso, pode-se afirmar que este trabalho se reveste de atualidade e importância, porque seu escopo é exatamente chamar os integrantes do meio acadêmico e a sociedade para refletirem sobre a realidade jurídica, política, cultural, econômica e social dos grupos minoritários brasileiros. 
Nesse sentido, a literatura e o direito andam de mãos dadas, a fim de apontar os defeitos e tecer críticas à sociedade e, nessa seara, a crônica demonstra como as minorias são as primeiras a perecerem quando a sociedade está em decadência e, agindo assim, toda ela ruirá, visto que os tubarões não possuem critério algum de exclusão.

O Estado, evidentemente, apresenta-se como devedor da tutela política e social de proteção das minorias sociais, pois trata diferentemente pessoas de graus semelhantes de vulnerabilidade, mas isso ainda não é o mais grave, pois foi mostrado que a conformação das pessoas pertencentes aos grupos minoritários é o pior adversário na mudança social.

Afirmou-se isto em virtude de que o estudo do discurso da servidão voluntária explica como as minorias sociais se autodeclaram merecedoras dos estigmas e propagam isso por toda a sociedade, uma vez que não possuem autoconfiança nas suas identidades e que realmente são merecedoras dos lugares de opressão, que estão localizados na sociedade.

Ao longo desta pesquisa, observou-se que o Brasil é um país de minorias, mas que, mesmo assim, é um país de invisíveis e feito para poucos, que promove a circulação de valores e estigmas, as quais também contribuem e muito para a marginalização dos indivíduos desses grupos minoritários.

Percebeu-se que com a análise e o esmiuçamento da teoria do princípio da igualdade relacional, é importante capacitar e dar vozes às minorias sociais, para que as pessoas possam ter uma vida autônoma, apoiando práticas de caráter anti-hegemômicas dos direitos fundamentais desses indivíduos.

Destarte, observou-se que a igualdade relacional é muito mais do que a igualdade formal e material juntas, pois é preciso que tanto o Estado crie políticas públicas, bem como os agentes da sociedade ajudem a efetivar tais políticas por meio da propagação de valores que promovam uma transformação cultural, com o intuito de tornar as pessoas tidas como minorias em sujeitos de seu próprio discurso e, claro, isso tudo para que a igualdade "realmente" seja a profissão de fé do Estado brasileiro. 


\section{REFERÊNCIAS}

ANDERSON, Elizabeth. What is the point of equality. Ethics, v. 109, n. 2, 1999.

BITTAR, Eduardo C. B.; ALMEIDA, Guilherme Assis de. Curso de filosofia do direito. 13. ed. rev., atual. e ampl. São Paulo: Atlas, 2018.

BOÉTIE, Etienne De La. Discurso da servidão voluntária. Tradução: Laymert Garcia dos Santos. Comentários: Claude Lefort. Pierre Clastres e Marilena Chauí. Editora Brasiliense. São Paulo, 1982.

BUENO, Roberto. O papel da literatura na reconstrução das subjetividades. Em tempo, Marília, v. 10, 2011.

CABRAL, João Francisco Pereira. Mito da caverna de Platão. Brasil Escola. Disponível em $<$ https://brasilescola.uol.com.br/filosofia/mito-caverna-platao.htm>. Acesso em: 27 ago. 2018.

CARMO, Claudio Márcio do. Grupos minoritários, grupos vulneráveis e o problema da (in)tolerância: uma relação linguístico-discursiva e ideológica entre o desrespeito e a manifestação do ódio no contexto brasileiro. Revista do Instituto de Estudos Brasileiros. n. 64. São João Del Rei. ago. 2016.

COUTINHO, Afrânio. Notas de teoria literária. 2. ed. Petrópolis: Vozes, 2008.

COVER, Robert M. Nomos e narração. Anamorphosis Revista internacional de direito e literatura. vol. 2, n. 2, tradução de Luis Rosenfield, 1983.

DEPUTADOS, Câmara dos. Homens brancos representam $80 \%$ dos eleitos para a Câmara. Disponível em: <http://www2.camara.leg.br/camaranoticias/noticias/POLITICA/475684HOMENS-BRANCOS-REPRESENTAM-71-DOS-ELEITOS-PARA-A-CAMARA.html>. Acesso em: 20 ago. 2018.

DIRCIN, Simpósio Regional Direito e Cinema em Debate. Direito cinema+literatura+música. Disponível em: <http://dircin.com.br/2018/o-evento>. Acesso em: 15 ago. 2018.

FRASER, Nancy. Transnationalizing the public sphere. Cambridge: Polity, 2014.

Recognition without ethics? Theory, culture e society, v. 18, n. 2-3, 2001.

GODOY, Arnaldo Sampaio de Moraes. Direito \& literatura. Curitiba: Juruá Editora, 2002.

JUSBRASIL. Lei 3629/03: lei 3629 de 28 de agosto de 2003. Disponível em: <https://cm-riode-janeiro.jusbrasil.com.br/legislacao/261000/lei-3629-03>. Acesso em: 22 ago. 2018.

MOREIRA, Adilson José. Cidadania sexual: estratégia para ações inclusivas. Belo Horizonte: Arraes Editores, 2017.

NUNES JÚNIOR, Vidal Serrano. A cidadania social na Constituição de 1988: estratégias de positivação e exigibilidade judicial dos direitos sociais. São Paulo: Editora Verbatim, 2009. 
PORTIS, Edward. Citizenship and personal identity. Polity, v. 1, n. 3, 1988.

RAMIRO, Caio Henrique Lopes. Direito, literatura e a construção do saber jurídico: Paulo Leminski e a crítica do formalismo jurídico. Revista de informação legislativa. Brasília a. 49, n. 196, out./dez. 2012.

RANGEL, Tauã Lima Verdan. A proteção constitucional das minorias à luz do posicionamento contramajoritário do STF: direitos fundamentais e dignidade da pessoa humana. Conteudo Juridico, Brasilia-DF: 06 abr. 2017. Disponivel em: <http://www.conteudojuridico.com.br/?artigos\&ver=2.588839\&seo=1>. Acesso em: 04 set. 2018.

RDL, Rede Brasileira Direito e Literatura. Direito \& literatura. Disponível em: $<$ http://www.rdl.org.br/pt/direito-e-literatura>. Acesso em: 10 ago. 2018.

RODRIGUES, Lucas de Oliveira. Minorias. Disponível em: $<$ https://mundoeducacao.bol.uol.com.br/sociologia/minorias.htm>. Acesso em: 18 ago. 2018.

SARLET, Ingo Wolfgang. A eficácia dos direitos fundamentais: uma teoria geral dos direitos fundamentais na perspectiva constitucional. 12. ed. rev. atual. e ampl. Porto Alegre: Livraria do Advogado Editora, 2015.

SCHEMMEL, Christian. Distributive and relational equality. Politics, philosophy and economics, v. 11, n. 3, 2011.

SMETAL, Sindicato dos Metalúrgicos de Sorocaba e Região. Minorias sociais: a busca por mais representatividade. Disponível em: <https://www.smetal.org.br/noticias/minoriassociais-a-busca-por-mais-representatividade/20160906-162935-q729>. Acesso em: 20 ago. 2018.

SOARES, Leonela Otilia Sauter; OLIVEIRA JÚNIOR, José Alcebíades. Machado de Assis e os direitos humanos: contribuição da literatura para a interpretação jurídica. In: CONGRESSO NACIONAL DO CONPEDI. Niteroi: CONPEDI, 2012.Disponível em: <http://www.publicadireito.com.br/artigos/?cod=b9cfe8b6042cf759>. Acesso em: 22 ago. 2018.

STRECK, Lenio Luiz. Juiz diz que réu, apesar de ser "de classe média”, é mau. Fujamos! Conjur. Disponível em: <https://www.conjur.com.br/2018-jul-23/streck-juiz-reu-apesarclasse-media-mau-fujamos>. Acesso em: 18 ago. 2018.

TRINDADE, Andre Karam. Direito e literatura: reflexões teóricas. Porto Alegre: Livraria do advogado, 2008.

VERÍSSIMO, Luís Fernando. Peças íntimas. 2. ed. Porto Alegre: L\&PM, 1990. 